\title{
A multidisciplinary UAV- And ground-geophysical mapping of complex mineralisations in an inter-tidal coastal Zone, Brittany (France)
}

Døssing, A.; Martelet, G.; Rasmussen, T. Mac K.; Gloaguen, E.; Lima Simões da Silva, E.; Linde, J.

Published in:

Proceedings of the 3rd Conference on Geophysics for Mineral Exploration and Mining

Link to article, DOI:

$10.3997 / 2214-4609.202020146$

Publication date:

2020

Document Version

Publisher's PDF, also known as Version of record

Link back to DTU Orbit

Citation (APA):

Døssing, A., Martelet, G., Rasmussen, T. M. K., Gloaguen, E., Lima Simões da Silva, E., \& Linde, J. (2020). A multidisciplinary UAV- And ground-geophysical mapping of complex mineralisations in an inter-tidal coastal Zone, Brittany (France). In Proceedings of the 3rd Conference on Geophysics for Mineral Exploration and Mining (pp. 1-5). European Association of Geoscientists and Engineers. https://doi.org/10.3997/2214-4609.202020146

\section{General rights}

Copyright and moral rights for the publications made accessible in the public portal are retained by the authors and/or other copyright owners and it is a condition of accessing publications that users recognise and abide by the legal requirements associated with these rights.

- Users may download and print one copy of any publication from the public portal for the purpose of private study or research.

- You may not further distribute the material or use it for any profit-making activity or commercial gain

- You may freely distribute the URL identifying the publication in the public portal 
A Multidisciplinary UAV- and Ground-Geophysical Mapping of Complex Mineralisations in an Inter-Tidal Coastal Zone, Brittany (France)

A. Døssing ${ }^{1}$, G. Martelet ${ }^{2}$, T. Mack Rasmussen ${ }^{3}$, E. Gloaguen², E. Lima Simões da Silva ${ }^{1}$, J. Linde $^{1}$

${ }^{1}$ DTU Space, Technical University of Denmark; ${ }^{2}$ French Geological Survey (BRGM); ${ }^{3}$ Luleå Technical University

\section{Summary}

Getting reliable geophysical and geological 3D models of the subsurface is an absolute necessity for successful resources exploration. Here, we show how novel UAV-borne geophysical mapping can be extremely valuable for mapping potential new exploration areas that are difficult to access by foot, such as hard rock inter-tidal zones and boulder beaches. We show the results from a multidisciplinary geophysical campaign of highly magnetic dikes and granites along a boulder beach in Brittany, France. Our mapping is carried out using customized geophysical sensor systems with high quality sensors. These include in particular a special designed UAV-towed magnetometer bird and multispectral system for large area mapping purposes. The UAV-borne mapping is supplemented by ground-based gamma-ray spectrometry data and ground-based magnetic gradiomety data. The results clearly demonstrate the value of UAV-borne systems in difficult areas as compared to traditional mapping methods as well as the value of combining various geophysical sensors for exploring the economic geology. All UAV-borne data were collected during two days, while the groundbased data - covering only the inner and dry part of the beach - were collected over seven days. 


\section{NEAR SURFACEE GEOSCIENCE'20}

\section{Introduction}

Getting reliable geophysical and geological 3D models of the subsurface is an absolute necessity for successful resources exploration and requires the integration of surface geology with various detailed geophysical data, such as magnetic data, gamma-ray spectroscopy data, hyperspectral data, and topography data. However, the acquisition of high-quality geophysical data is often hampered by expensive airborne surveying techniques (e.g. by helicopter or airplane) or by time-consuming and incomplete ground-based surveying techniques.

With the increased reliability of small survey-grade Unmanned Aerial Vehicles (UAVs), opportunities arise for carrying out high-quality geophysical surveys in previously inaccessible areas, at significantly reduced costs and with a much higher flexibility in the planning than before.

As part of the EIT-RM MuVerDrone project, we have developed various integrated hardwaresoftware UAV-borne geophysical systems, with the specific purpose of mapping raw materials. Our purpose is to test all the systems combined at selected mineral exploration case studies in Sweden, France and Norway and show - by integrated data analysis - the advantage of combining multiple UAV-borne sensor systems for efficient resources exploration. Here, we show data and analysis from a UAV-borne geophysical case study in Brittany in France.

\section{Field area}

The location of the field area is shown in Figure 1. The area consists of two distinct areas off PerrosGuirec and Ploumanac (Figure 2).

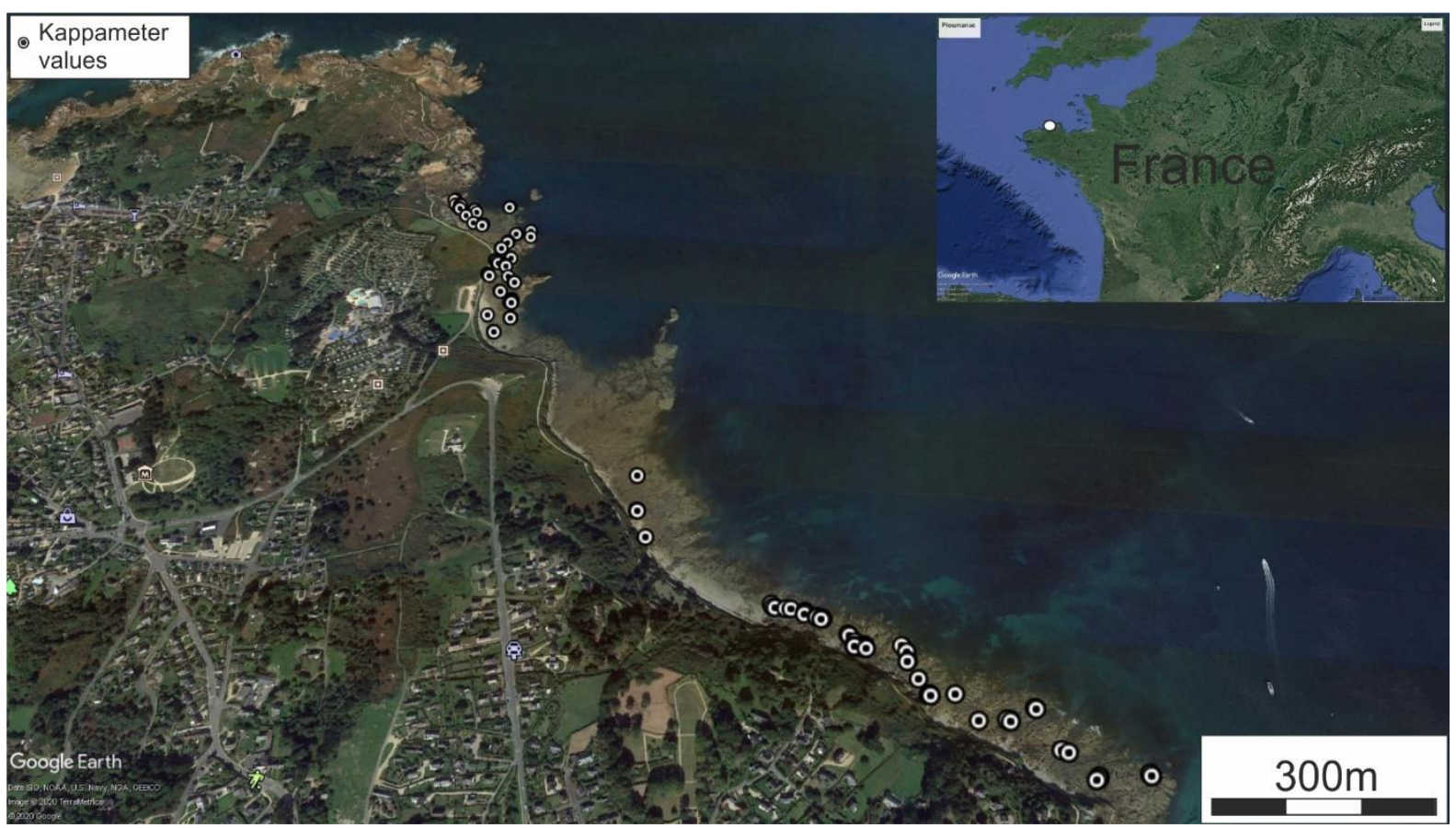

Figure 1 Field area located along and off the coast of Perros-Guirec and Ploumanac in Brittany, France. UAV-borne geophysical mapping was carried out along the entire coast line and about 200m into the water. Black-white dots are locations of kappameter (magnetic susceptibility measurements). 


\section{NEAR SURFACECE $\triangle$ GEOSCIENCE'?}

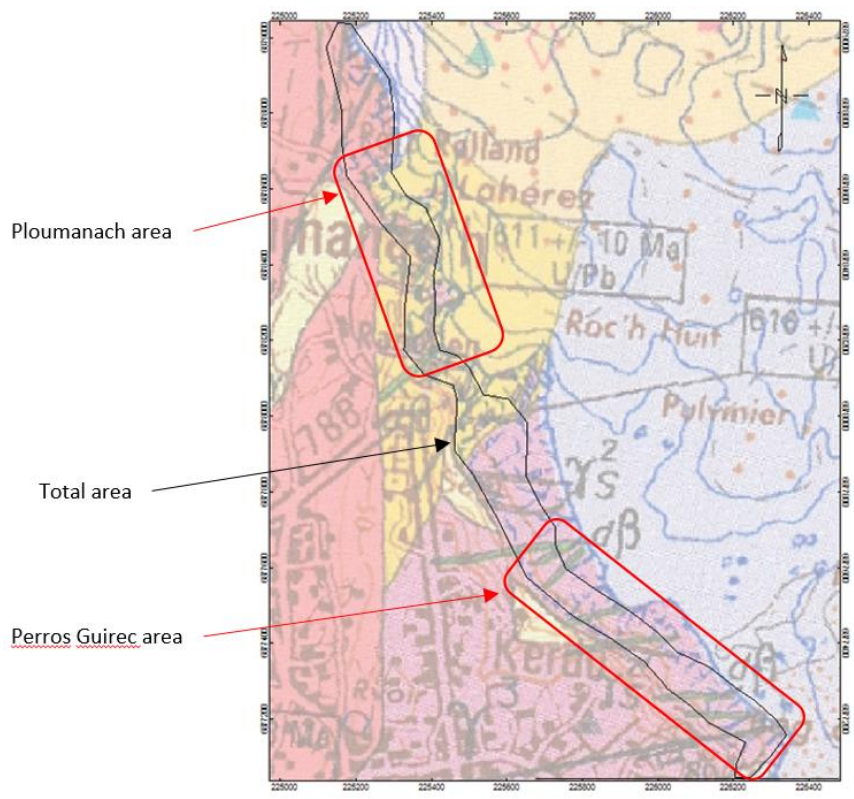

Figure 2 Field areas: Perros-Guirec to the southeast and Ploumanac to the northwest

The field areas are characterized by strong tides (up to $10 \mathrm{~m}$ during high tide). During low tide, the accessible parts of the beach consist entirely of small to large boulders, making the beach extremely difficult to survey on foot.

The outcropping geology of the area (Figure 2 ), consists of icartian gneisses (the oldest in France), two types of granites of very different ages as well as numerous crosscutting dikes with mineralisation concentrates. Interestingly, some of the dikes are associated with pseudo-skarn with high concentrations of magnetite in the vicinity of one of the two types of intrusives.

\section{Survey systems and Surveys}

For UAV-borne geophysical mapping of the coast line, we used a single sensor magnetometer bird, carrying a Rubidium absolute sensor. The bird was carried $4.5 \mathrm{~m}$ below a survey-grade UAV. In addition, we mapped the area by a UAV-borne multispectral sensor system and photogrammetry system. Originally, we intended to carry out UAV-borne gamma-ray spectrometry and LiDaR mapping. However, unfavourable weather conditions did not allow further UAV-borne campaigns during the available period of the campaign. Instead gamma-ray mapping was carried out on foot together with ground-based magnetic gradiometer surveys on the inner (dry) part of the beach during low tide.

\section{Results}

In Figure 3, we show the results of topographic (by optical imaging) and multispectral mapping of the coastline. Arrows indicate locations of the NE-SW cross-cutting dykes, which are clearly visible as dark patches in the optical data as well as green patches in the near-infrared data. An almost 1-to-1 correlation is found between the topographic/multispectral data and the UAV-borne magnetic data (Figure 4) and ground-based gamma-ray (Figure 5). 


\section{NEAR SURFACE GEOSCIENGE'20}

\section{EAGE}

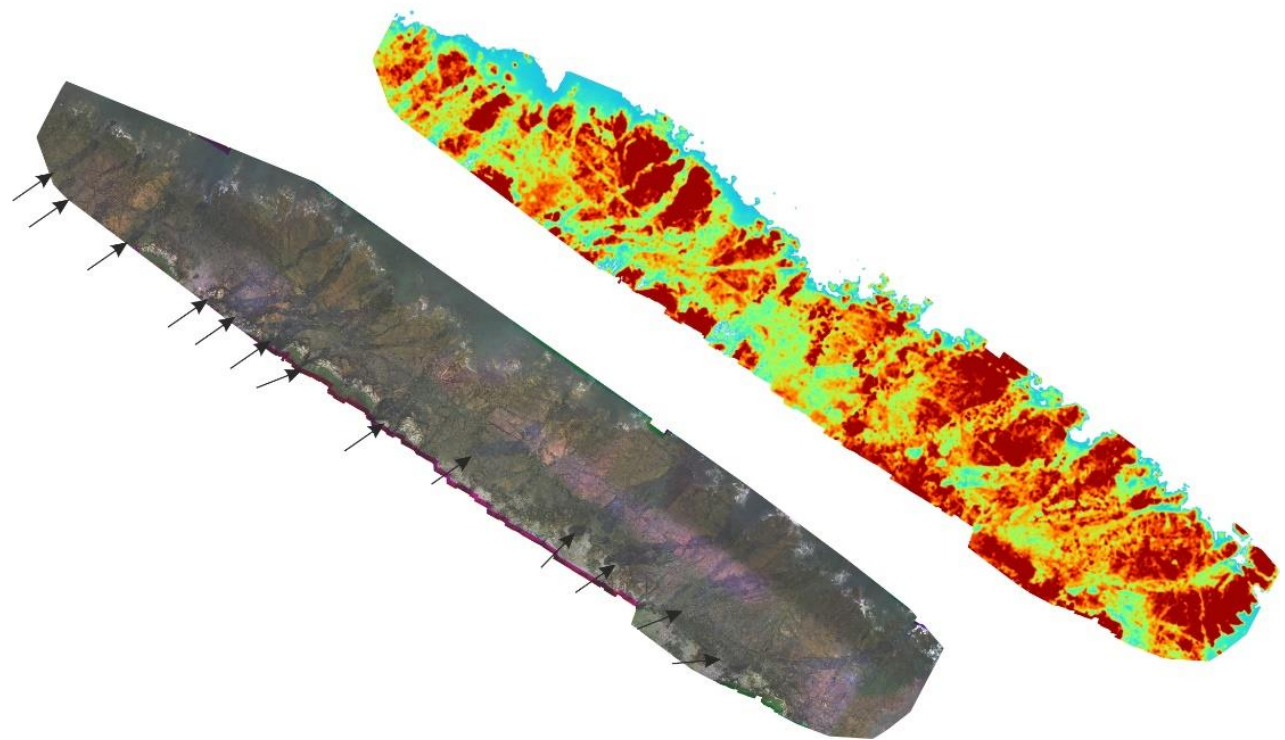

Figure 3 Topographic (lower picture) and multispectral/near-infrared (upper picture) mapping of the inner beach off Perros-Guirec. Black arrows in the topographic image are locations of magnetite-rich cross-cutting dikes. The area mapped is about $1 \mathrm{~km}$ long and covers the southeastern Perros Guirec field area.

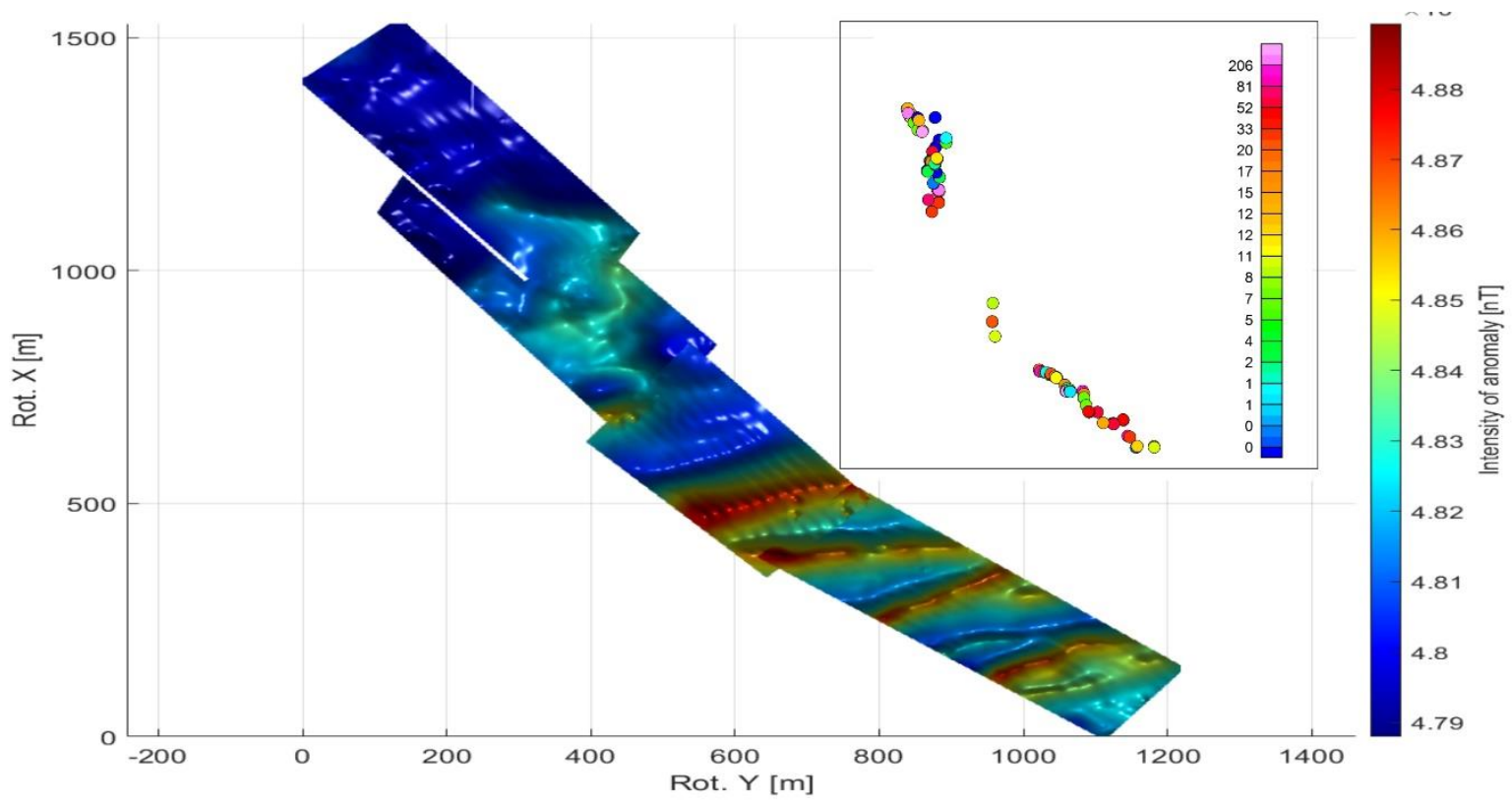

Figure 4 UAV-borne magnetic mapping of the entire coastline off Ploumanac and Perros-Guirec, using a towed single-sensor magnetometer with an absolute Rubidium magnetometer. Notice the strong magnetic signature of the cross-cutting dykes to the southeast in the area off Perros-Guirec. These dikes correlate well with the observations in Figure 3 and 5. In total, the magnetic survey consists of four individual surveys and a total area of almost $2 \mathrm{~km} \times 0.2 \mathrm{~km}$. Inset figure: Kappameter susceptibility measurements (SI) that will be used to constrain the final $3 D$ geological modelling. 


\section{NEAB SUPFFACE $\triangle$ GEOSCIENCE'?}

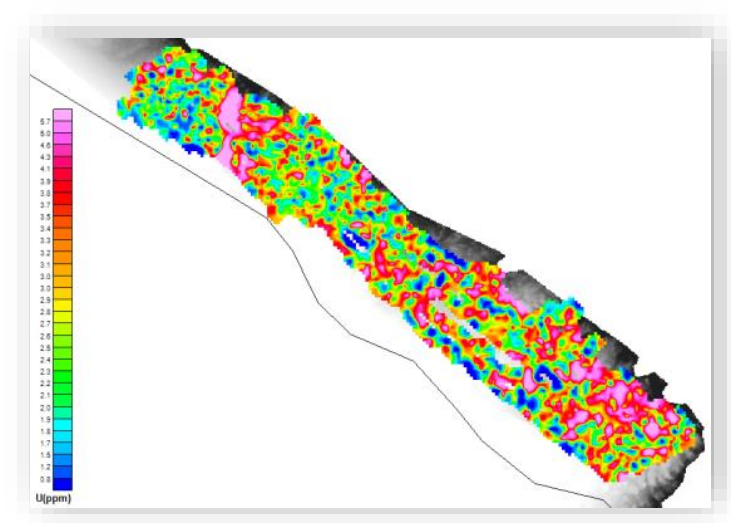

Uranium

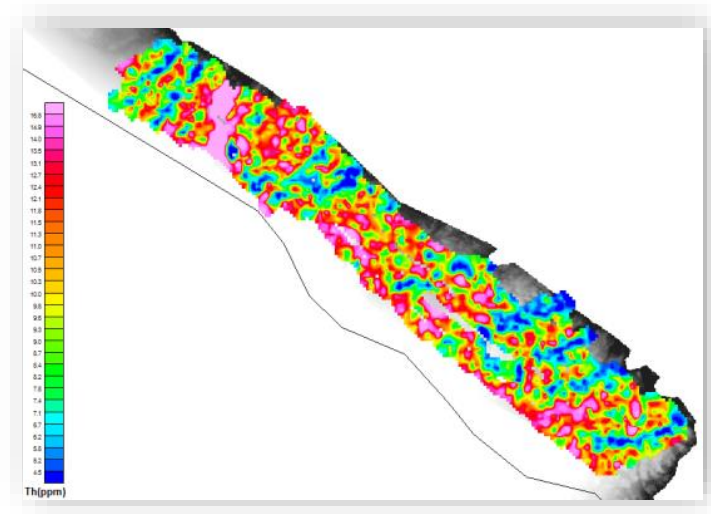

Thorium

\section{EAGE}

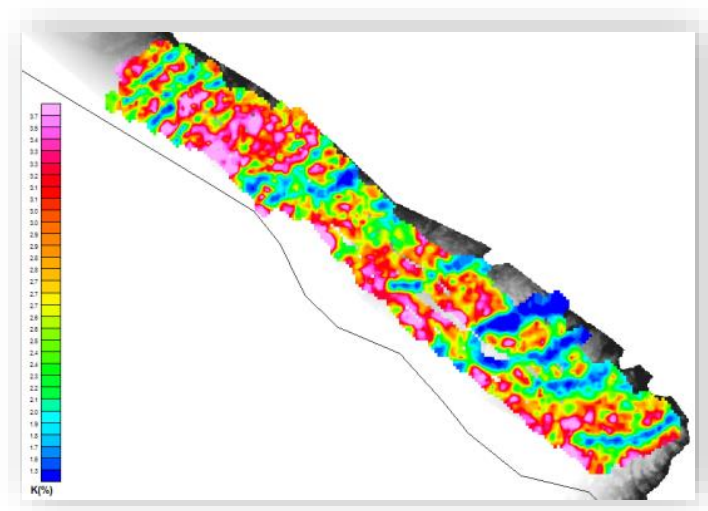

Potassium

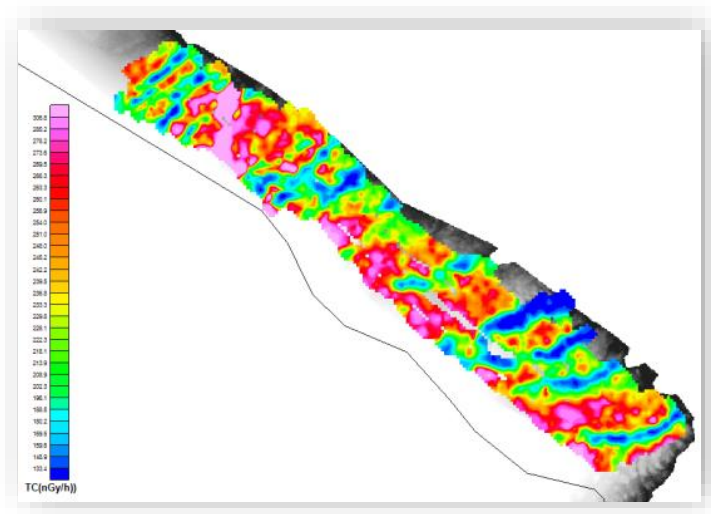

Tot. count

Figure 5 Results of ground-based gamma-ray spectrometry. Notice the strong correlation with the optical, multispectral and magnetic data in Figures 3 and 4.

\section{Conclusion}

UAV-borne geophysical mapping is extremely efficient in areas that are difficult to access by foot, e.g. inter-tidal zones and boulder beaches. Here, we have shown the results from a multidisciplinary geophysical campaign of highly magnetic dikes and granites in Brittany, France, with the purpose of mapping complex surface geology in an inter-tidal zone using UAV-borne geophysical sensor systems. The results clearly demonstrate the value of UAV-borne systems in difficult areas as compared to traditional mapping methods as well as the value of combining various geophysical sensors for exploring the geology. Moving forward, we will finalize the analysis the geophysical data by carrying out a 3D geological modelling of the cross-cutting dikes, constrained by all geophysical data as well as kappameter susceptibility measurements along the beach.

\section{Acknowledgements}

The MuVerDrone project is funded by EIT RM and consists of partners DTU Space (Denmark), BRGM (France), LTU (Sweden) and Sky-Watch A/S (Denmark). 